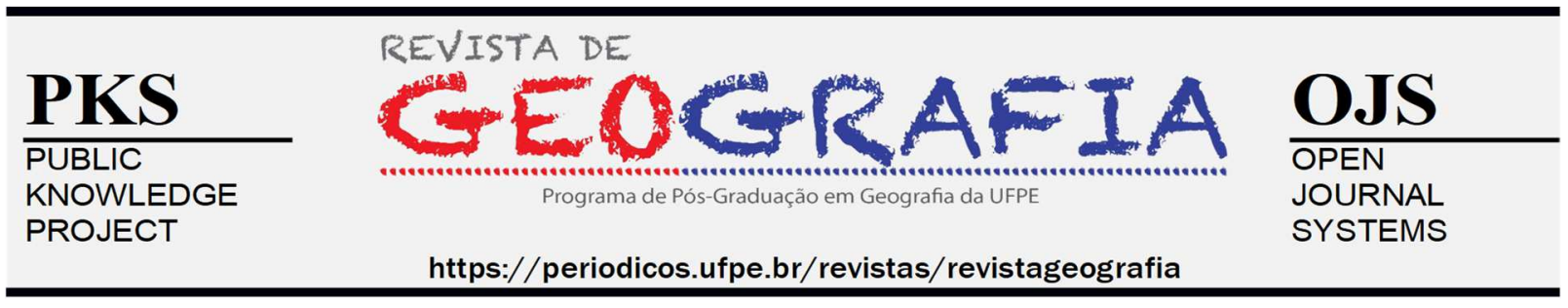

\title{
PERCEPÇÃO AMBIENTAL SOBRE FLORESTAS URBANAS COMO ESTRATÉGIA TURÍSTICA E DE DESENVOLVIMENTO ECONÔMICO/SUSTENTÁVEL
}

\author{
Charles Costa Coelho ${ }^{1}$, Ana Carolina Boschetti ${ }^{2}$, Maria Raquel Kanieski ${ }^{3}$, Marcelo Diniz \\ Vitorino $^{4}$
}

\begin{abstract}
${ }^{1}$ Mestre em Engenharia Florestal, Universidade Regional de Blumenau. E-mail: ccoelho.florestal@gmail.com. ORDCID: https://orcid.org/0000-0002-5594-5584

${ }^{2}$ Mestra em Engenharia Florestal, Universidade Regional de Blumenau. E-mail: anaboschetti@hotmail.com. ORDCID: https://orcid.org/0000-0001-8557-2443

3 Universidade do Estado de Santa Catarina. Prof. ${ }^{a}$ Dr. $^{\text {a }}$ do Programa de Pós-Graduação em Engenharia Florestal/UDESC. E-mail: raquel.kanieski@udesc.br; ORDCID: https://orcid.org/0000-0003-1078-5641

${ }^{4}$ Universidade Regional de Blumenau. Prof. Dr. do Programa de Pós-Graduação em Engenharia Florestal/FURB. E-mail: diniz@furb.br; ORDCID: https://orcid.org/0000-0002-9537-6275
\end{abstract}

Artigo recebido em 31/01/2021 e aceito em 06/03/2021

\section{RESUMO}

O turismo urbano com o passar do tempo ganhou força e hoje é reconhecido globalmente, representando a principal fonte de renda de diferentes cidades. O objetivo do estudo foi investigar a percepção da população sobre florestas urbanas como atrativo turístico. O trabalho foi realizado nas cidades de São Joaquim, Urubici e Urupema no estado de Santa Catarina. A pesquisa foi aplicada tipo Survey. Em cada cidade foram aplicados 300 questionários. Como critério de amostragem para aplicação do formulário de percepção, procurou-se englobar todos os bairros presentes em cada cidade. No total foram entrevistadas 900 pessoas ( $45 \%$ Masc. $155 \%$ Fem.), em que $76 \%$ da população acredita que a arborização urbana pode ser um atrativo turístico. Os entrevistados apontaram fatores como parques urbanos, túnel verde com arborização viária e principalmente a utilização de espécies nativas endêmicas da região para arborização. Há uma diferença estatística nas respostas quando a comparação é realizada em grupo com as características sociodemográficas, o que pode ser consequência de maior facilidade de acesso e informações sobre os benefícios da arborização urbana. Assim, é necessária a criação de ações coletivas entre gestores públicos e comunidade, com propósito de subsidiar e fomentar a arborização nos municípios.

Palavras-chave: arborização; planejamento; turismo. 


\title{
ENVIRONMENTAL PERCEPTION ON URBAN FORESTS AS A TOURIST AND ECONOMIC/SUSTAINABLE DEVELOPMENT STRATEGY
}

\begin{abstract}
Urban tourism over time has gained strength and is now recognized globally, representing the main source of income in different cities. The aim of the study was to investigate the population's perception of urban forests as a tourist attraction. The work was carried out in the cities of São Joaquim, Urubici and Urupema in the state of Santa Catarina. The survey was applied as a survey. In each city, 300 questionnaires were applied. As a sampling criterion for applying the perception form, we sought to encompass all the neighborhoods present in each city. In total, 900 people were interviewed $(45 \%$ Masc. $155 \%$ Fem.), In which $76 \%$ of the population believes that urban afforestation can be a tourist attraction. The interviewees pointed out factors such as urban parks, a green tunnel with road afforestation and mainly the use of native species endemic to the region for afforestation. There is a statistical difference in the answers when the comparison is made in a group with the sociodemographic characteristics, which may be a consequence of greater ease of access and information on the benefits of urban afforestation. Thus, it is necessary to create collective actions between public managers and the community, with the purpose of subsidizing and promoting afforestation in the municipalities.
\end{abstract}

Keywords: afforestation; planning; tourism.

\section{PERCEPCIÓN AMBIENTAL SOBRE LOS BOSQUES URBANOS COMO ESTRATEGIA TURÍSTICA Y DESARROLLO ECONÓMICO / SOSTENIBLE}

\section{RESUMEN}

El turismo urbano a lo largo del tiempo ha ido ganando fuerza y ahora es reconocido a nivel mundial, representando la principal fuente de ingresos en diferentes ciudades. El objetivo del estudio fue investigar la percepción que tiene la población de los bosques urbanos como atractivo turístico. El trabajo se llevó a cabo en las ciudades de São Joaquim, Urubici y Urupema en el estado de Santa Catarina. La encuesta se aplicó como una Encuesta. En cada ciudad se aplicaron 300 cuestionarios. Como criterio muestral para la aplicación del formulario de percepción, se buscó abarcar todos los barrios presentes en cada ciudad. En total, se entrevistaron 900 personas (45\% Masc./55\% Fem.), En las que el $76 \%$ de la población cree que la forestación urbana puede ser un atractivo turístico. Los entrevistados señalaron factores como los parques urbanos, un túnel verde con forestación vial y principalmente el uso de especies endémicas nativas de la región para la forestación. Existe una diferencia estadística en las respuestas cuando la comparación se hace en un grupo con las características sociodemográficas, lo que puede ser consecuencia de una mayor facilidad de acceso e información sobre los beneficios de la forestación urbana. Por ello, es necesario generar acciones colectivas entre los gestores públicos y la comunidad, con el propósito de subsidiar y promover la forestación en los municipios.

Palabras clave: repoblación forestal; planificación; turismo. 


\section{INTRODUÇÃO}

A atividade turística representa a principal fonte de renda de diferentes cidades. Quando bem desenvolvida não gera apenas o aumento do rendimento e fortalecimento na economia, mas também sustenta projetos de revitalização urbana, podendo ser um importante instrumento de preservação e conservação do patrimônio histórico, cultural e ambiental (SCOTT, 2008; BARROS, 2012; HE et al., 2018). No Brasil, o turismo foi reconhecido como atividades realizadas por pessoas físicas durante viagens e estadas em lugares diferentes do seu entorno habitual, por um período inferior a um ano, com finalidade de lazer, negócios e entre outras. Existem basicamente 11 categorias de turismo, sendo os mais conhecidos: religioso, cultural, rural e urbano. (BRASIL, 2008a).

Com o passar do tempo o desenvolvimento do turismo urbano ganhou força e hoje é reconhecido globalmente (CONNELL et al., 2009) e tornou-se foco de pesquisa nas últimas décadas (LIU, 2003; GÖSSLING et al., 2009; XU \& FOX, 2014; SU \& SWANSON, 2017; YUAN et al., 2018). O turista urbano pode ser motivado pelas mais variadas razões, tais como, visita a parentes e amigos, estudos, negócios, compras, eventos culturais, esportivos e entre outros. Apesar dos diferentes motivos, os turistas urbanos têm um objetivo em comum, que é o de vivenciar a experiência turística com comodidade, segurança e satisfação (BARROS, 2012; MOSQUERA \& SANCHÉZ, 2011).

Diante do reconhecimento global e crescente tendência, surge o conceito "Turismo Verde Urbano" e "Ecoturismo Urbano". Em ambos os casos, a modalidade surgiu a partir da necessidade de valorizar e revitalizar as áreas verdes urbanas para que turistas e residentes pudessem usufruir desses espaços. Esse reencontro do homem com a natureza no ambiente urbano se constitui em um forte apelo turístico em que a paisagem urbana com características naturais, deixa de ser um mero cenário para se tornar o próprio atrativo turístico (DODDS \& JOPPE, 2001; BARROS, 2012).

Assim, Florestas Urbanas ou Arborização Urbana são definidas como "a soma de toda a vegetação lenhosa, associada dentro e ao redor de assentamentos humanos, variando de pequenas comunidades a grandes regiões metropolitanas" (MILLER, 1988). Desse modo, florestas urbanas incluem árvores pré-existentes e plantadas nas calçadas, ruas, canteiros centrais, jardins públicos e privados, parques urbanos e áreas verdes que rodeiam rios urbanos e área de preservação permanente (APP) urbana.

Deng et al. (2010), apontam que as florestas urbanas têm a capacidade de aumentar 
significativamente a beleza das áreas urbanas e melhorar a experiência dos turistas, funcionando como um fator importante na atração de turistas e como um complemento de outros ímãs do turismo urbano.

Entretanto, os gestores públicos municipais responsáveis pelas florestas urbanas são confrontados com o desafio de equilibrar os benefícios e custos associados a esses recursos (DWYER et al., 1992). Na cidade de Savannah, na Geórgia-USA, as florestas urbanas são uma das principais atrações turísticas (DENG et al., 2010), mas o crescimento populacional é uma ameaça contínua às árvores da cidade. Portanto, informações sobre a extensão e magnitude das áreas verdes podem ajudar significativamente no planejamento e no gerenciamento de recursos florestais no meio urbano (DWYER et al., 1992; MAJUNDAR et al., 2011).

Em virtude das informações mencionadas, o investimento e o planejamento das florestas urbanas são indispensáveis, pois pode resultar em ganhos diretos para o município, como é o caso da economia, que pode ser aumentada conforme a demanda turística. Assim, o propósito do estudo foi investigar as características sociodemográficas (gênero, idade e grau de escolaridade) dos moradores de São Joaquim, Urubici e Urupema no estado de Santa Catarina, juntamente com a percepção ambiental dos indivíduos sobre florestas urbanas como atrativo turístico, buscando responder as seguintes perguntas: (i) As características sociodemográficas influenciam na percepção populacional em relação às florestas urbanas? (ii) os benefícios das florestas urbanas são reconhecidos pela população das cidades amostradas? (iii) os entrevistados acreditam que a arborização pode ser um elemento para o turismo?

\section{MATERIAL E MÉTODOS}

Área de estudo

O trabalho foi realizado nas cidades de São Joaquim, Urubici e Urupema, ambas localizadas na Região Sul, Estado de Santa Catarina (Figura 01). Os municípios fazem parte da Serra Catarinense, caracterizado pelas altas altitudes, frio e pelo forte apelo turístico (IBGE, 2010a). Atualmente, a arborização presente nas três áreas de estudo é resultado do que foi implantado pelos primeiros moradores da cidade. Com o passar dos anos, aliado ao crescimento das cidades sem nenhum planejamento voltado para arborização urbana, as árvores acabaram sendo retiradas para dar espaço a construção civil, diminuindo ainda mais o número de 
indivíduos presentes na arborização urbana (Tabela 1).

Figura 1. Localização geográfica das três cidades de estudo (SC).
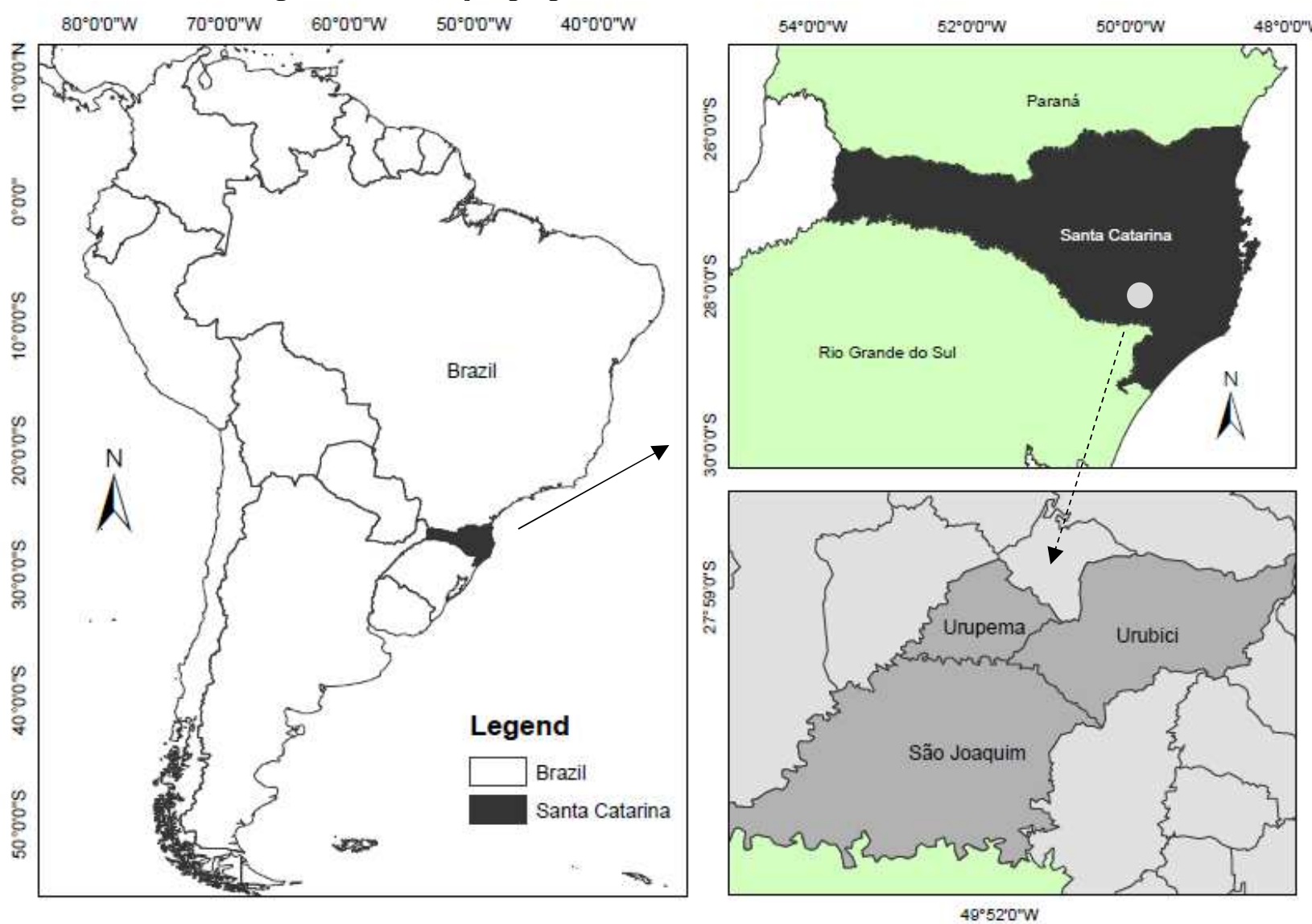

Fonte: Os Autores, 2020.

Tabela 1. Distribuição populacional dos municípios por área urbana x área rural e relação de vias públicas arborizadas por cidade.

\begin{tabular}{|c|c|c|c|c|}
\hline \multirow{2}{*}{ CIDADE } & \multicolumn{3}{|c|}{ População } & \multirow{2}{*}{$\begin{array}{l}\text { Arborização } \\
\text { Viária }(\%) *\end{array}$} \\
\hline & Urbana & Rural & Total & \\
\hline São Joaquim & 17.573 & 7.239 & 24.812 & 16,0 \\
\hline Urubici & 7.069 & 3.633 & 10.699 & 20,6 \\
\hline Urupema & 1.232 & 1.250 & 2.482 & 16,6 \\
\hline
\end{tabular}

*Arborização de vias públicas: [domicílios urbanos em face de quadra com arborização/domicílios urbanos totais] x100 (IBGE, 2018a,b,c).

Nota: Dados da população refere-se ao último censo realizado pelo Instituto Brasileiro de Geografia e estatística (IBGE) no ano de 2010. 


\section{Metodologia}

Para avaliação de percepção ambiental foi empregado um questionário misto (APENDICE), divido em dois grupos, afirmações $(n=7)$ e perguntas $(n=2)$, embasado na metodologia de Brun (2008) e Viana (2013). A pesquisa foi aplicada tipo Survey, caracterizada por utilizar de instrumentos predefinidos para obtenção de dados quantitativos. Também foram coletados dados mediante entrevistas, com observação direta e notas sobre comentários dos entrevistados perante a questão, de tal modo que complementasse a leitura e interpretação de dados obtidos no questionário. Assim, em cada cidade foram aplicados 300 questionários. A coleta de dados ocorreu no período de setembro de 2018 a novembro de 2019.

Como critério de amostragem para aplicação do formulário de percepção, procurou-se englobar todos os bairros presentes em cada cidade, principalmente o Bairro Centro, onde se encontra a maior frequência de pessoas devido ao comércio, lazer e trabalho. Para aplicação do questionário optou-se pela escala de Likert, na qual foram adotados graus de concordância para as respectivas notas de 0 a 4 , correspondendo, respectivamente, a "discordo totalmente", “discordo", "não concordo e nem discordo", "concordo" e "concordo plenamente", acrescidos da opção "não sei".

Os dados foram submetidos ao teste de Saphiro-Wilk com o objetivo de avaliar a normalidade, em seguida foram aplicados os testes não paramétricos de Kruskal-Wallis e Teste Qui-Quadrado $\left(\mathrm{X}^{2}\right)$. Também foi aplicado uma análise de correspondência (AC), que permite uma simplificação de dados complexos, visualizando o grau de associação do conjunto e das categorias das variáveis qualitativas (HAIR et al., 2009). As análises foram processadas no Software BioEstat 5.3. e PAST versão 3.25.

\section{RESULTADOS E DISCUSSÃO}

O perfil dos participantes da pesquisa, no que tange a informações objetivas, mostra características referentes aos parâmetros de idade, gênero e escolaridade. No total, foram entrevistadas 900 pessoas, sendo 409 homens e 491 mulheres. De acordo com Alreck \& Serrle (1995), nos surveys, independentemente do tamanho da população amostral, a quantidade de 300 entrevistados apresenta um nível estatístico satisfatório de confiança, com erro amostral inferior a $10 \%$ sobre a população real. Valores acima de 300 resultam em um incremento baixo, 
perante o erro amostral, o que no que lhe concerne é considerado pouco viável em relação ao custo/benefício.

A proporção encontrada dos entrevistados dos sexos masculino e feminino em cada uma das cidades foi semelhante, sendo, respectivamente, $42 \%$ e 58\% em São Joaquim, 45\% e 55\% em Urubici, e 49\% e 51\% em Urupema. A faixa etária predominante foi a de 18 a 24 anos nas cidades de São Joaquim e Urubici, diferindo de Urupema, em que a classe com maior número de entrevistados foi a de 35 a 44 anos. Esse estudo conseguiu abranger todas as faixas etárias (Figura 2).

Figura 2. Distribuição das faixas etárias dos entrevistados por área de estudo.

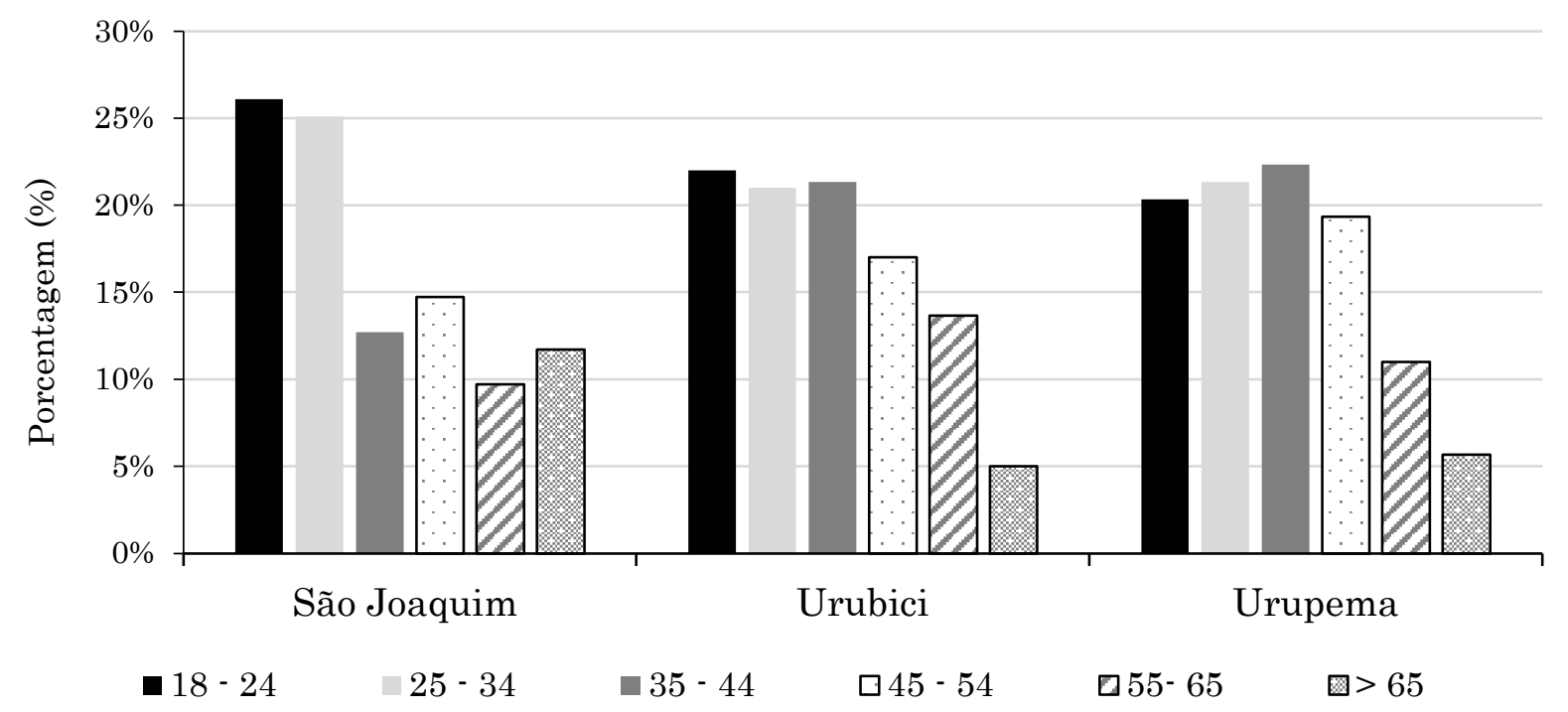

A maioria dos entrevistados possui ensino médio completo para ambas as áreas de estudo, contemplando 35\% em São Joaquim, 35\% em Urubici e 27\% em Urupema (Figura 3). A escolaridade é uma variável sociodemográfica importante para estudos com percepção ambiental, pois ajuda a identificar o perfil da população amostrada, correlacionando o nível de instrução dos entrevistados com a arborização urbana. A falta ou o baixo nível de escolaridade pode não estar diretamente associado à percepção da arborização, no entanto, pode influenciar um certo grau de dificuldade dos entrevistados em responder a questões mais complexas (ROPPA et al., 2007; SUFIA et al., 2018). 
Figura 3. Distribuição do grau de escolaridade dos entrevistados por área de estudo.

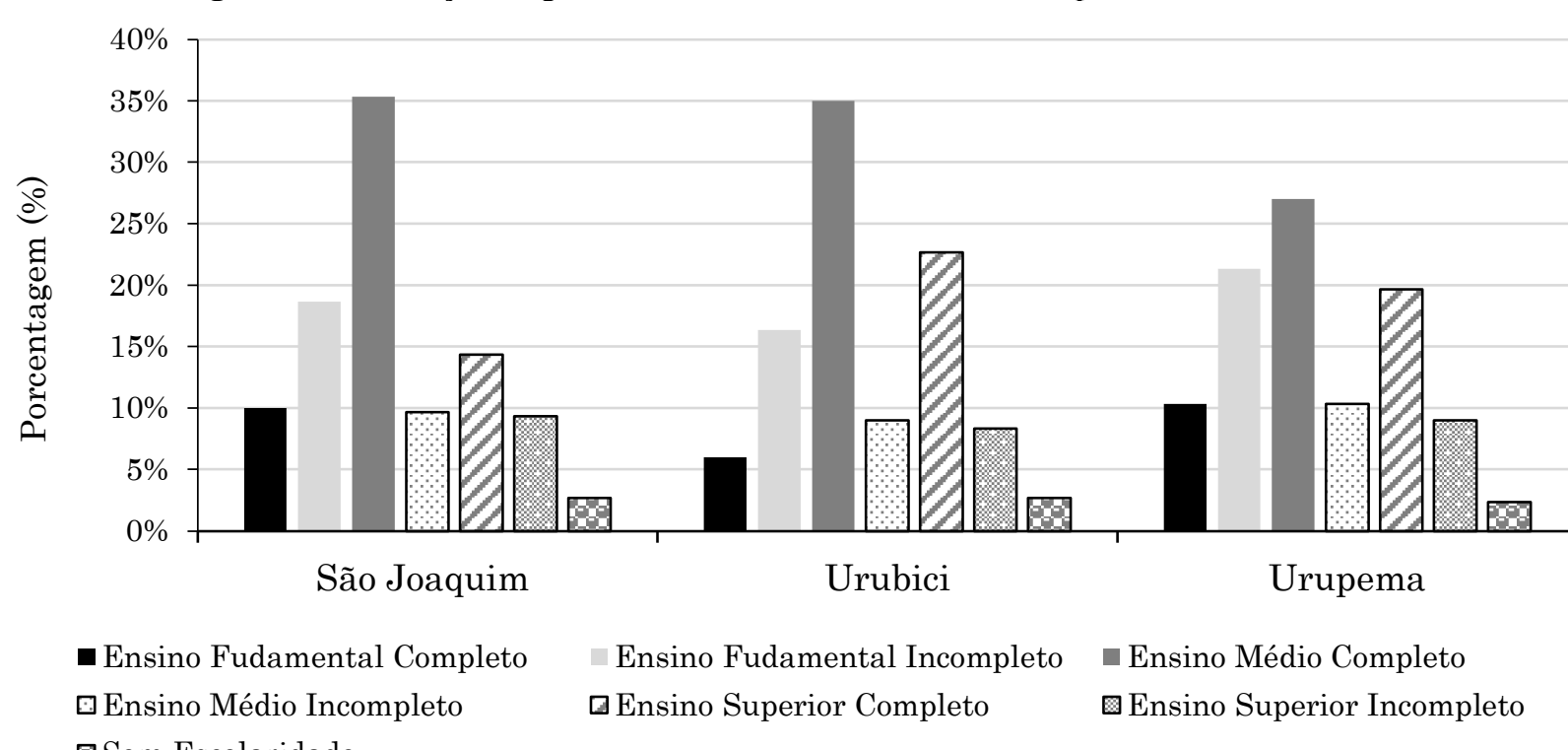

曰em Escolaridade

Após colhidas informações sociodemográficas sobre os participantes do questionário, os entrevistados foram expostos a cinco questões afirmativas e quatro interrogativas, ambas direcionadas a temática florestas urbanas, totalizando ao todo nove questões. A maioria dos entrevistados discorda da afirmação "1 - As árvores não deveriam ser plantadas nas cidades". Na qual a população de Urupema e São Joaquim destacaram-se pela grande porcentagem que discorda plenamente (26,33 e 27,33\%) e discorda da afirmação (44,67 e 54,00\%), inclusive com manifestação de surpresa e questionamento se era possível alguém não gostar do plantio de árvores na cidade. Em contrapartida, em Urubici, 58,00\% dos entrevistados disseram que não discordam e não concordam com a afirmação.

Parte dos entrevistados que concordaram ou concordaram plenamente com a afirmação justificavam suas respostas aos conflitos com imobiliários urbanos, placas, fiação elétrica e sujeira causada pelas flores. O mesmo comportamento é observado em outros trabalhos que questionaram sobre as desvantagens da arborização urbana (RODRIGUES et al., 2010; HO et al., 2015; NOVAIS, et al., 2017; LIMA et al., 2018; ALMEIDA et al., 2019).

Em relação aos aspectos positivos, diante da afirmação "2 - As árvores nas cidades deixam o local mais saudável e fresco" a maioria dos entrevistados reconhece de forma "indireta" os benefícios das florestas urbanas. Somando as respostas "Concordo" e "Concordo plenamente" as frequências foram superiores a 82,00\% nas três cidades de estudo. 
Expostos diante da afirmativa "3 - As árvores apresentam mais vantagens do que problemas", 8,00\% dos entrevistados responderam que "Não discordam e nem concordam". Em Urupema, a frequência dos entrevistados que optaram por responder "Discordo" e "Discordo plenamente", somadas, foram cerca de 6,00\%, superior ao encontrado em Urubici e São Joaquim com 2,43 e 3,00\% respectivamente. No entanto, a soma dos graus de concordâncias "Concordo" e "Concordo plenamente" foram superiores a $82 \%$ nas três cidades. Valores próximos foram encontrados por Viana (2013), em seu estudo realizado no município de São Paulo-SP, no qual 70,00\% dos entrevistados, disseram concordar que as árvores apresentam mais vantagens do que desvantagem.

Quando questionados se "4 - Investir em árvores na cidade é desperdício de dinheiro público", foi observado que nos três municípios a maioria dos entrevistados respondeu que “discordavam plenamente" e "discordavam", sendo, 28,00 e 60,67\% em Urubici, 30,00 e 49,33\% em Urupema, 32,67 e 58,00\% em São Joaquim, respectivamente. As reclamações da atuação do poder público foram recorrentes nos comentários destas respostas.

Em relação à afirmação "5 - Minha cidade é bem arborizada", a maior parte dos entrevistados de São Joaquim e Urubici discordam (62,33 e 52,33\%, respectivamente). Em Urupema 48,49\% concordaram com a questão, porém, quando questionados, os entrevistados direcionavam os olhares para fora da cidade, pois Urupema apresenta uma topografia ondulada e é cercada por morros cobertos de vegetação, tornando a percepção de arborização urbana subjetiva para leigos. Desse modo é compreensível o equívoco entre conceitos de arborização urbana e a vegetação ocorrente em topos de morro próximos do meio urbano.

Roppa et al. (2007), em seu trabalho de percepção sobre arborização urbana em Santa Maria-RS, aponta que este estilo de pergunta tende a ser muito subjetiva, dependendo em grande parte da maior ou menor vivência do morador no local, pelo fato que muitos tendem a avaliar a arborização de sua rua ou mesmo da cidade, pela que se encontra em frente à sua casa. Outro aspecto que pode influenciar o grau de concordância, é o fator cultural e local onde o entrevistado cresceu, pois aqueles que cresceram na zona rural, tendem a ter uma visão mais crítica para os espaços verdes urbanos, quando comparado com pessoas que viveram em sua maioria em áreas urbanas.

Sobre o questionamento " 6 - Você gostaria que tivesse mais árvores plantadas na cidade?", somando os graus de concordância "Concordo" e "Concordo plenamente" a frequência foi superior a 72,00\%. Em Urupema, 20,73\% dos entrevistados discordaram do 
enunciado, atrelando ao frio da região, pois a sombra gerada pelas copas das árvores, projetada sobre as casas e calçadas, deixa o ambiente ainda mais frio e úmido.

Em relação a questão “7 - Você percebe que a arborização atrai fauna/pássaros?”, mais de $95,00 \%$ dos entrevistados concordaram com a pergunta, sendo o resultado semelhante para os três municípios estudados. Ao final de cada resposta, os entrevistados comentavam sobre o festival do Papagaio-Charão (Amazona pretrei) e Papagaio-do-peito-roxo (Amazona vinaceae), espécies que constam no Livro Vermelho da Fauna Brasileira Ameaçada de Extinção (ICMBio, 2018) e na portaria . $^{\circ}$ 444/2014 (BRASIL, 2014b). O festival ocorre anualmente na região e atrai milhares de turistas fomentando a economia local e regional da Serra Catarinense.

Para realização da análise de correspondência (AC) considerou-se as respostas dadas pelas questões de 1 a 7 (Figura 4). Por meio do mapa nota-se a formação de três grupos, o primeiro engloba as questões 1 e 4 com maior discordância sobre se as árvores não deveriam ser plantadas nas cidades e investir em árvores é desperdício do dinheiro público.

O segundo grupo é formado pelas questões 2, 3, 6 e 7, que dizem respeito à percepção dos benefícios/vantagens da arborização e se os entrevistados gostariam que tivessem mais árvores plantadas nas cidades, mais próximos dos pontos 3 e 4, ou uma visão mais positiva sobre as florestas urbanas.

O terceiro e último grupo, questão 5, relaciona sobre se as cidades em estudo são bem arborizadas, estando mais próximo do grau "Não discordo e não concordo" e "Não sei", corroborando com as observações indiretas relatadas pelos entrevistadores, na qual os entrevistados direcionavam os olhares para fora da cidade, olhando para os topos de morro. 
Figura 4. Gráfico de correspondência (AC), com associação entre as questões Q1 a Q7 (representado pela cor preta) e grau de concordância (representado pela cor azul) envolvendo as populações de São Joaquim, Urubici e Urupema em Santa Catarina.

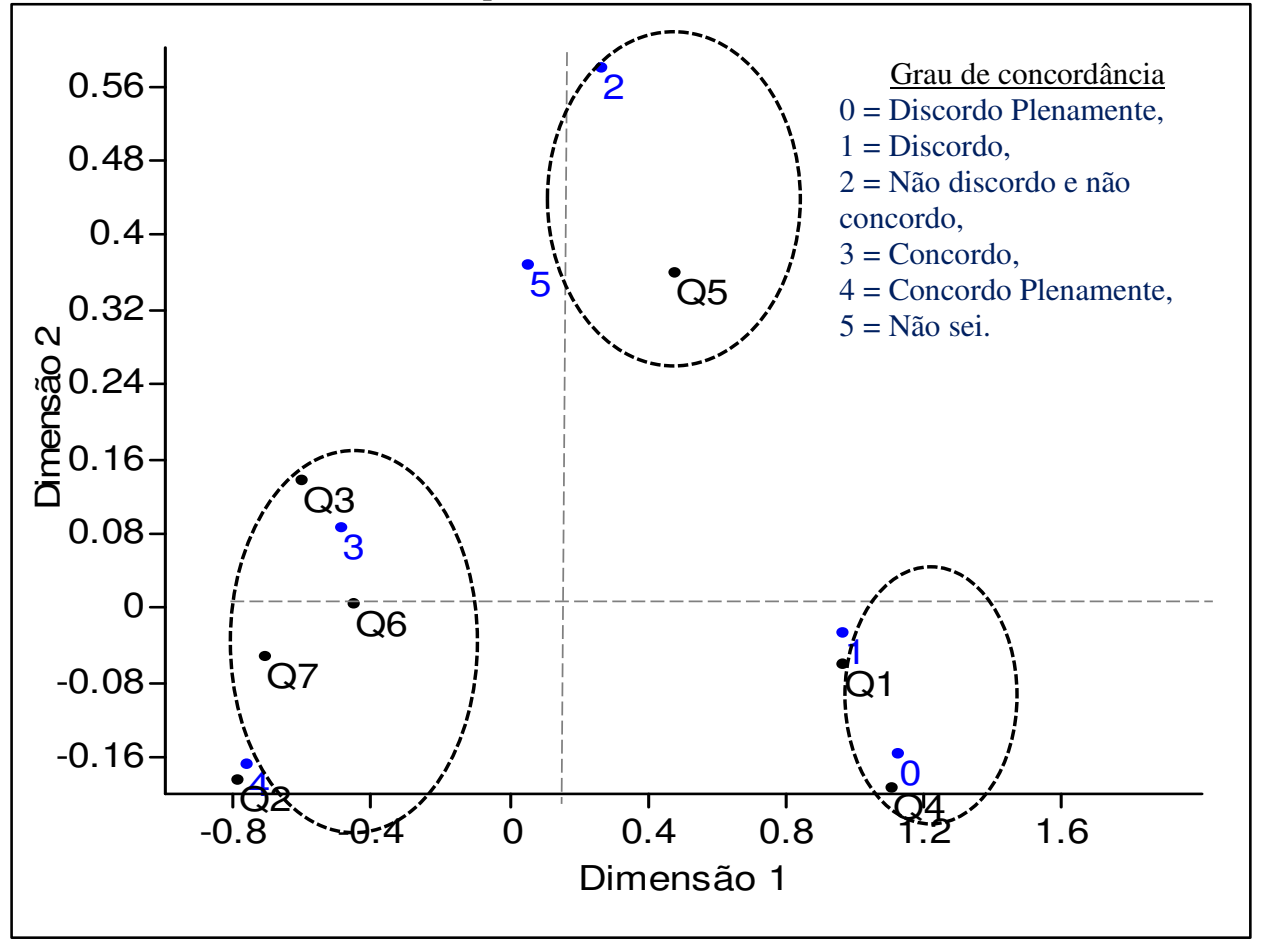

O turismo rural é uma das atividades economicamente mais importantes da Serra Catarinense. Para avaliar se a arborização urbana contribui para essa atividade, os entrevistados foram questionados com a pergunta " 8 - Você acredita que arborização urbana pode atrair turista para a cidade?" $76 \%$ da população amostral acreditam que sim. Os entrevistados apontaram fatores como parques urbanos, túnel verde com arborização viária e principalmente a utilização de espécies nativas endêmicas da região para arborização.

O resultado encontrado corrobora com o trabalho de Barros (2012), no qual 90\% dos turistas entrevistados em Maringá-PR, apontam que a arborização viária da cidade é um atrativo turístico da região, e, com o estudo de Raskovic e Decker (2015), onde examinaram a influência das árvores na percepção e descobriram que as praças com árvores podem aumentar a disposição das pessoas de revisitar e ficar mais tempo naquele ambiente do que sem árvores. Assim, fica nítido o papel das árvores na promoção de sensação prazerosa diretamente ou indiretamente aos visitantes.

Com objetivo de verificar a diferença entre as populações, foi aplicado o teste não paramétrico Kruskal-Wallis para os dados demográficos. Os valores encontrados apontaram 
que não existe diferença estatística significativa entre as cidades, para com a variável sexo ( $\mathrm{gl}=1, \mathrm{p}=0,999, \alpha=0,05)$, faixa etária $(\mathrm{gl}=5, \mathrm{p}=0,998, \alpha=0,05)$ e grau de escolaridade ( $\mathrm{gl}=6$, $\mathrm{p}=0,859, \alpha=0,05)$. Portanto, optou-se pelo agrupamento dos dados das três cidades para aplicação do teste Qui-quadrado.

Quando aplicado o teste qui-quadrado $\left(\mathrm{X}^{2}\right)$ para verificação entre a variável resposta Sim/Não e o sexo (Fem./Mas.), não houve diferença significativa $\left(\mathrm{X}^{2}=1,13\right.$ e p=0,288) (Tabela 2), ou seja, não há associação entre as variáveis, portanto, a percepção quanto ao potencial turístico voltado para arborização, não advêm das diferenças de gênero.

Tabela 2. Frequência e teste de significância para o conjunto de dados das três cidades (São Joaquim, Urubici e Urupema), sobre as características sociodemográficas relacionados a pergunta "Você acredita que arborização urbana pode atrair turista para a cidade?".

\begin{tabular}{l|c|cc|ccc}
\hline \multicolumn{2}{c}{} & \multicolumn{2}{c|}{ N. Observado } & \multicolumn{3}{c}{ X $^{2}$ teste } \\
\hline \multirow{2}{*}{ Sexo } & & Sim & Não & X $^{2}$ valor & GL & p-valor \\
\hline \multirow{5}{*}{ Faixa Etária } & Fem. & 381 & 110 & 1,13 & 1 & 0,288 \\
& Mas. & 305 & 104 & - & - & - \\
\hline & $18-24$ & 172 & 33 & 32,01 & 5 & $5,91 \mathrm{E}-06^{*}$ \\
& $25-34$ & 169 & 33 & - & - & - \\
& $35-44$ & 124 & 46 & - & - & - \\
& $45-54$ & 114 & 39 & - & - & - \\
& $55-65$ & 68 & 35 & - & - & - \\
\multirow{5}{*}{ Grau de Escolaridade } & $>65$ & 39 & 28 & - & - & - \\
\hline & SE & 16 & 7 & 27,91 & 6 & $9,77 \mathrm{E}-06^{*}$ \\
& EFC & 52 & 27 & - & - & - \\
& EFI & 110 & 59 & - & - & - \\
& EMC & 231 & 61 & - & - & - \\
& EMI & 76 & 11 & - & - & - \\
& ESC & 133 & 37 & - & - & - \\
& ESI & 68 & 12 & - & - & - \\
\hline
\end{tabular}

Legenda: SE = Sem Escolaridade; EFC = Ensino Fundamental Completo; EFI = Ensino Fundamental Incompleto; EMC $=$ Ensino Médio Completo; EMI $=$ Ensino Médio Incompleto; ESC $=$ Ensino Superior Completo e ESI $=$ Ensino Superior Incompleto.

$\mathrm{X}^{2}=$ Símbolo do teste de Qui-quadrado; $\mathrm{GL}=$ Grau de liberdade; $\mathrm{p}=$ Nível de significância do teste.

$*$ Significativo $\alpha=0,05 \%$. 
As variáveis faixa etária $\left(X^{2}=32,01\right.$ e $\left.\mathrm{p}=5,91 \mathrm{E}-06\right)$ e grau de escolaridade $\left(\mathrm{X}^{2}=27,91 \mathrm{e}\right.$ p=9,77E-06) apresentaram diferenças significativas, destacando a faixa etária 25-34 anos $(n=202)$ e o grau de escolaridade Ensino Médio Completo $(n=292)$. Assim, dependendo da faixa etária e grau de escolaridade, existe uma diferença na percepção sobre a ligação do turismo com arborização. Cabe ressaltar que o teste Qui-quadrado $\left(\mathrm{X}^{2}\right)$, apenas aponta se existe ou não associação entre as variáveis, e não onde ocorre essa associação dentro dos grupos avaliados.

Da população que se sensibiliza em contribuir financeiramente, o número dos entrevistados do sexo feminino (275) foi maior que o sexo masculino (196), juntos, correspondem a 53\% da população amostral. Os não aptos pela contribuição $(47,66 \%)$, justificavam que já contribuíam por meio de impostos, e que mesmo se ajudassem, não teriam a certeza do retorno do valor destinado aos cuidados das árvores urbanas. Santos et al., (2018), em seu trabalho realizado no bairro Santa Tereza, em Tefé-AM, aponta que $81 \%$ dos entrevistados estariam dispostos a contribuir financeiramente para a manutenção da arborização de suas ruas. Entretanto, valores divergentes foram encontrados por Lacerda et al. (2010), no qual 83,5\% dos entrevistados na cidade de São José de Piranhas-PB, apontaram que não estariam dispostos em contribuir.

Quando aplicado o teste qui-quadrado $\left(\mathrm{X}^{2}\right)$ para verificação entre a variável resposta ( $\mathrm{R} \$ 5,00$ por ano; $\mathrm{R} \$ 5,00$ a 10,00 por ano; > R \$ 10,00 por ano) e o sexo (Fem./Mas.), não houve associação $\left(\mathrm{X}^{2}=1,08\right.$ e p=0,583), portanto, a sensibilidade de manter um meio ambiente equilibrado e investir em áreas verdes nas cidades não se relacionou às diferenças de gênero (Tabela 03). 
Tabela 3. Frequência e teste de significância aplicado para o conjunto de dados das três cidades (São Joaquim, Urubici e Urupema), sobre as características sociodemográficas em relação a nível de contribuição financeira para manutenção das árvores urbanas.

\begin{tabular}{l|c|ccc|ccc}
\hline \multicolumn{2}{l|}{} & \multicolumn{3}{c|}{ N. Observado } & \multicolumn{3}{c}{$\mathbf{X}^{2}$ teste } \\
\hline \multirow{2}{*}{ Sexo } & & R\$ 5,00 & R\$ 5,00 -10,00 & $>$ R\$ 10,00 & $\mathbf{X}^{2}$ valor & GL & p-valor \\
\hline \multirow{5}{*}{ Faixa Etária } & Fem. & 89 & 100 & 86 & 1,08 & 1 & 0,583 \\
& Mas. & 55 & 78 & 63 & - & - & - \\
\hline & $18-24$ & 32 & 49 & 40 & $22, .27$ & 5 & $0,014 *$ \\
& $25-34$ & 30 & 50 & 46 & - & - & - \\
& $35-44$ & 24 & 32 & 27 & - & - & - \\
& $45-54$ & 25 & 34 & 19 & - & - & - \\
& $55-65$ & 22 & 8 & 9 & - & - & - \\
& $>65$ & 11 & 5 & 8 & - & - & - \\
\hline \multirow{5}{*}{ Grau de } & SE & 2 & 5 & 0 & 39,10 & 6 & $401 \mathrm{E}-04^{*}$ \\
& EFC & 14 & 9 & 7 & - & - & - \\
& EFI & 35 & 24 & 11 & - & - & - \\
& EMC & 55 & 58 & 54 & - & - & - \\
& EMI & 14 & 21 & 15 & - & - & - \\
& ESC & 16 & 42 & 43 & - & - & - \\
& ESI & 8 & 19 & 19 & - & - & - \\
\hline
\end{tabular}

Legenda: $\mathrm{SE}=$ Sem Escolaridade; EFC = Ensino Fundamental Completo; EFI = Ensino Fundamental Incompleto; $\mathrm{EMC}=$ Ensino Médio Completo; EMI $=$ Ensino Médio Incompleto; ESC $=$ Ensino Superior Completo e ESI = Ensino Superior Incompleto;

$\mathrm{X}^{2}=$ Símbolo do teste de Qui-quadrado; $\mathrm{GL}=$ Grau de liberdade; $\mathrm{p}=$ Nível de significância do teste.

$*=$ Significativo $\alpha=0,05 \%$.

Entretanto, as variáveis faixa etária $\left(\mathrm{X}^{2}=22,27\right.$ e $\left.\mathrm{p}=0,014\right)$ e grau de escolaridade $\left(X^{2}=39,10\right.$ e p=4,01E-04) apresentaram diferenças significativas, ou seja, há associação entre as variáveis, na qual os mais jovens (18-24 e 25-34 anos) estão mais dispostos em contribuir financeiramente. Esse resultado pode ser o reflexo da Política Nacional de Educação Ambiental (Brasil, 1999c), que ordena que qualquer instituição de ensino atuante no Brasil, deve inserir a educação ambiental como um componente permanente nas grades de ensino. Para o grau de escolaridade EMC $(n=167)$ e ESC $(n=101)$ foi onde se observou o maior número de pessoas dispostas a pagar pela manutenção das árvores urbana, corroborando com os dados de Araújo (2016), em que houve uma predominância dos entrevistados nas classes EMC (37\%) e ESC $(21 \%)$.

Desse modo, dependendo da faixa etária e grau de escolaridade, existe uma diferença na percepção sobre o conhecimento e a importância das árvores na cidade, fazendo-se necessária a criação de programas de educação ambiental envolvendo a temática florestas 
urbanas tanto nas escolas municipais, estaduais e para a população em geral, especialmente os mais idosos, criando ações extensionistas para toda comunidade de São Joaquim, Urubici e Urupema.

Embora na literatura haja diversos trabalhos envolvendo percepção ambiental relacionada à arborização urbana (LACERDA et al., 2010; GROSS et al., 2012; LOURENÇO, 2017; ALMEIDA et al., 2019), análises quali-quantitativas como as realizadas no presente trabalho, podem auxiliar na elaboração de políticas públicas direcionadas ao planejamento ambiental de uma cidade, considerando as vontades e anseios da população (SUFIA et al., 2018).

Pesquisas envolvendo essa temática provocam reflexões em quem reside no local, visto que são eles que sentem diretamente o impacto da qualidade da arborização a partir de práticas de conservação e manejo florestal urbano nos indivíduos arbóreos, promovido pelos gestores municipais e companhias de energia elétrica (QUADROS \& FREI, 2009; RODRIGUES et al., 2010; SUFIA et al., 2018).

\section{CONCLUSÕES}

Há uma diferença estatística nas respostas quando a comparação é realizada em grupo com as características sociodemográficas, faixa etária e grau de escolaridade, o que infere ser consequência de maior facilidade de acesso e informações sobre os benefícios da arborização urbana, acerca do potencial turístico e disposição a pagar pelo manejo arbóreo urbano.

Os entrevistados conhecem diretamente e indiretamente os benefícios gerados pelas florestas urbanas, bem como, expressam que a destinação do dinheiro público para arborização urbana é uma forma de investimento ao turismo dos municípios.

Dos 900 entrevistados, 53\% demonstraram-se dispostos a contribuir financeiramente para a manutenção e monitoramento dessas áreas, e, 76\% acreditam que arborização urbana atrai turistas, fazendo-se necessária a criação de ações coletivas entre gestores públicos e comunidade, com propósito de subsidiar e fomentar a arborização nos municípios de São Joaquim, Urubici e Urupema.

Os dados gerados e as conclusões deste estudo fornecem informações úteis para a promoção do turismo urbano nas cidades de São Joaquim, Urubici e Urupema no estado de Santa Catarina. Desse modo, recomenda-se que as cidades continuem gerenciando a

$\begin{array}{llr}\text { Coelho et al., } 2021 & \text { ISSN 0104-5490 }\end{array}$


arborização urbana e elaborem programas que proporcionem oportunidades para a população e turistas, possam aprendam mais sobre as funções, benefícios e exclusividade das florestas urbanas da região da Serra Catarinense. Sugere-se que novos estudos voltados ao paisagismo ecológico com espécies arbóreas nativa da Fitorregião Floresta Ombrófila Mista sejam realizados, a fim de complementar com as informações do atual estudo, e que ambas as informações sejam apresentadas aos gestores para auxiliar na elaboração de planos de turismo.

\section{AGRADECIMENTOS}

O presente trabalho foi realizado com apoio da Coordenação de Aperfeiçoamento de Pessoal de Nível Superior-Brasil (CAPES) - Código de Financiamento 001. O trabalho a campo, contou também com parcerias das secretarias municipais de Turismo e Meio Ambiente dos três municípios envolvidos no estudo, sendo São Joaquim, Urubici e Urupema, além do Centro de Treinamento de São Joaquim da Empresa de Pesquisa Agropecuária e Extensão Rural de Santa Catarina - CETREJO/EPAGRI.

\section{REFERÊNCIAS}

ALMEIDA, E. P., DOS SANTOS FERNANDES, S. P., SOUTO, P. C. (2019). Arborização urbana na percepção da população do distrito de Iara no Ceará. Revista da Sociedade Brasileira de Arborização Urbana, 14 (2), 16-30.

ALRECK, P. L. \& SERRLE, R. B. (1995). The survey research handboo: guidelin and strategies for conducting a survey. (p. 60-85). New York: Mcgraw-hill.

ARAÚJO, C. R. G. (2016). Turismo em Lagoas Costeiras e a Valoração Ambiental em Osório-RS (Dissertação de Mestrado) Programa de Pós-Graduação em Turismo e Hospitalidade, Universidade de Caxias do Sul - UCS, Caxias do Sul - RS.

BARROS, R. DE A. (2012). O potencial turístico da arborização viária de Maringá/PR sob a ótica dos turistas. Revista da Sociedade Brasileira de Arborização Urbana, 7 (2), 68-79.

BRASIL a (2008, 17 de setembro). Lei Federal n ${ }^{\circ} 11.771$, de 17 de setembro de 2008. Lei estabelece normas sobre a Política Nacional de Turismo. Brasília: Diário Oficial da União, seção 1.

BRASIL b. Ministério do Meio Ambiente (2014). Portaria no 444, de 17 de dezembro de 
2014. Dispõe sobre a Lista Nacional das Espécies da Fauna Brasileira Ameaçadas de Extinção. Brasília: Diário Oficial da União. Recuperado em 27 de março de 2020.

BRASIL c (1999, 27 de abril). Lei Federal no 9.795, de 27 de abril de 1999. Lei estabelece normas sobre a Política Nacional de Educação Ambiental. Brasília: Diário Oficial da União, seção 1 .

BRUN, F. G. K. (2008). Percepção sobre a arborização urbana no Bairro Camobi, Santa Maria-RS: estudo de um caso (Monografia-Especialização em Educação Ambiental). Universidade Federal de Santa Maria, Santa Maria.

CONNELL, J., PAGE, S. J., BENTLEY, T. (2009). Towards sustainable tourism planning in New Zealand: Monitoring local government planning under the Resource Management Act. Tourism Management, 30 (6), 867-877.

DENG, J., MARTÍN, J. D. (2010). Linking urban forests and urban tourism: a case of Savannah, Georgia. Tourism Analysis, 15 (2), 167-181.

DODDS, R., JOPPE, M. (2001). Promoting urban green tourism: The evelopment of the other map of Toronto. Journal of Vacation Marketing, 7 (3), 261-67.

DWYER, J. F., MCPHERSON, E. G., SCHROEDER, H. W., ROWNTREE, R. A. (1992). Assessing the benefits and costs of the urban forest. Journal of Arboriculture, 18 (1), 227 227.

GÖSSLING, S., HALL, C. M., WEAVER, D. (2009). Sustainable tourism futures: Perspectives on systems, restructuring and innovations. New York, EU.

GROSS, A., DORS, P., DE CAMPOS, K. A., DA SILVA, A. C., HIGUCHI, P. (2012). Percepção dos moradores e avaliação da arborização em bairros periféricos na cidade de Lages, SC. Revista da Sociedade Brasileira de Arborização Urbana, 7, (2), 24-36.

HAIR, J. F., ANDEROSON, R. E., TATHAM, R. L., BLACK, W.C. (2009). Análise multivariada de dados. Porta Alegre, Bookman.

HE, P.; HE, Y.; XU, F. (2018). Evolutionary analysis of sustainable tourism. Annals of Tourism Research, 69 (1), 76-89.

HO, T. L., KOVALSYKI, B., ZAMPRONI, K., BIONDI, D. (2015). Percepção dos moradores sobre a arborização de ruas da região central de Mandirituba/PR. Revista da Sociedade Brasileira de Arborização Urbana, 10 (3), 14-23.

INSTITUTO BRASILEIRO DE GEOGRAFIA E ESTATÍSTICA - IBGEa. (2010). Censo Demográfico - 2010. São Joaquim: IBGE. Recuperado em 27 de março de 2018. 
INSTITUTO BRASILEIRO DE GEOGRAFIA E ESTATÍSTICA - IBGEb. (2010). Censo Demográfico - 2010. Urubici: IBGE. Recuperado em 27 de março de 2018.

INSTITUTO BRASILEIRO DE GEOGRAFIA E ESTATÍSTICA - IBGEc. (2010). Censo Demográfico - 2010. Urupema: IBGE. Recuperado em 27 de março de 2018.

ICMBio, Instituto Chico Mendes de Conservação da Biodiversidade (2018). Livro Vermelho da Fauna Brasileira Ameaçada de Extinção (Volume III - Aves). Brasília: ICMBio.

LACERDA, N. P., SOUTO, P. C., DIAS, R. S., SOUTO, L. S., SOUTO, J. S. (2010). Percepção dos residentes sobre a arborização da cidade de São José de Piranhas-PB. Revista da Sociedade Brasileira de Arborização Urbana, 5 (4), 81-95.

LIMA, J. R., SOUSA, R. P., ALVES, G., FIGUERÔA, L., DE OLIVEIRA, E. (2018). Arborização: desafios em comunidade do semiárido brasileiro. Revista da Sociedade Brasileira de Arborização Urbana, 13 (1), 28-42.

LIU, Z. (2003). Sustainable tourism development: A critique. Journal of sustainable tourism, $11(6), 459-475$.

LOURENÇO, J. S. G. (2017). Percepção da população sobre a arborização da cidade de São João Del-Rei, MG. Revista da Sociedade Brasileira de Arborização Urbana, 12 (2), 62-72.

MAJUMDAR, S., DENG, J., ZHANG, Y., PIERSKALLA, C. (2011). Using contingent valuation to estimate the willingness of tourists to pay for urban forests: A study in Savannah, Georgia. Urban Forestry \& Urban Greening, 10 (4), 275-280.

MILLER, R. W., HAUER, R. J., WERNER, L. P. (2015). Urban forestry: planning and managing urban greenspaces. Waveland press, 2015.

MOSQUERA, L. N. \& SÁNCHEZ, M. (2011). A influência de valores pessoais na avaliação do uso econômico de espaços verdes periurbanos: uma aplicação da teoria da cadeia de meios-fins. Gestão de Turismo, 32 (4), 875-889.

NOVAIS, D. B., SOUTO, P. C., BARROSO, R. F., CAMAÑO, J. D. Z., FERREIRA, V. S. G. (2017). Arborização na cidade de Santa Helena na Paraíba: A percepção dos seus munícipes. Revista da Sociedade Brasileira de Arborização Urbana, 12 (1), 31-45.

QUADROS, L. S., FREI, F. (2009). Percepção ambiental dos residentes da cidade de Assis SP com relação à arborização viária da Avenida Rui Barbosa. Revista da Sociedade Brasileira de Arborização Urbana, 4 (2), 16-34.

RAŠKOVIC, S. \& DECKER, R. (2015). The influence of trees on the perception of urban Coelho et al., $2021 \quad$ ISSN 0104-5490 583 
squares. Urban Forestry \& Urban Greening, 14 (2), 237-245.

RODRIGUES, T. D., MALAFAIA, G., QUEIROZ, S. É. E., DE LIMA RODRIGUES, A. S. (2010). Percepção sobre arborização urbana de moradores em três áreas de Pires do RioGoiás. Revista de estudos ambientais, 12 (2), 47-61.

ROPPA, C., FALKENBERG, J. R., STANGERLIN, D. M., BRUN, F. G. K., BRUN, E. J., LONGHI, S. J. (2007). Diagnóstico da percepção dos moradores sobre a arborização urbana na Vila Estação Colônia-Bairro Camobi, Santa Maria-RS. Revista da Sociedade Brasileira de Arborização Urbana, 2 (2), 11-30.

SANTOS, M. O., SOUZA, L. P. S. M., OLIVEIRA, E. D., SILVA NETO, J. C. A., CELLA, W. (2018). Percepção ambiental sobre a arborização urbana no bairro Santa Tereza, Tefé, Amazonas, Brasil. O Espaço Geográfico em Análise, 44 (1), 231-241.

SCOTT, N. (2008). Urban Tourism and Environmental Issues. School of Tourism, The University of Queensland, Australia.

SU, L. J., HSU, M. K., SWANSON, S. (2017). The effect of tourist relationship perception on destination loyalty at a world heritage site in China: The mediating role of overall destination satisfaction and trust. Journal of Hospitality \& Tourism Research, 41 (2), 180-210.

SUFIA, M. C. S., SANTOS SOUZA, G., SIQUEIRA, M. V. B. M. (2018). Percepção ambiental sobre arborização urbana em regiões distintas do município de Bauru-SP. Revista da Sociedade Brasileira de Arborização Urbana, 13 (4), 15-28.

VIANA, S. M. (2013). Percepção e quantificação das árvores na área urbana do município de São Carlos (Tese de Doutorado). Escola Superior de Agricultura Luiz de Queiroz, Universidade de São Paulo, Piracicaba.

XU, F., FOX, D. (2014). Modelling attitudes to nature, tourism and sustainable development in national parks: A survey of visitors in China and the UK. Tourism Management, 45 (1), $142-158$.

YUAN, J., DENG, J., PIERSKALLA, C., KING, B. (2018). Urban tourism attributes and overall satisfaction: An asymmetric impact-performance analysis. Urban Forestry \& Urban Greening, 30 (1), 169-181. 


\section{APENDICE}

UNIVERSIDADE REGIONAL DE BLUMENAU

CENTRO DE CIÊNCIAS TECNOLÓGICAS

F U R B

ESTUDO DE PERCEPÇÃO SOBRE A QUALIDADE DA ARBORIZAÇÃO URBANA

Cidade de aplicação: $\square$ URUBICI $\square$ URUPEMA $\square$ SÃo JOAQUIM

Entrevistador: Data:

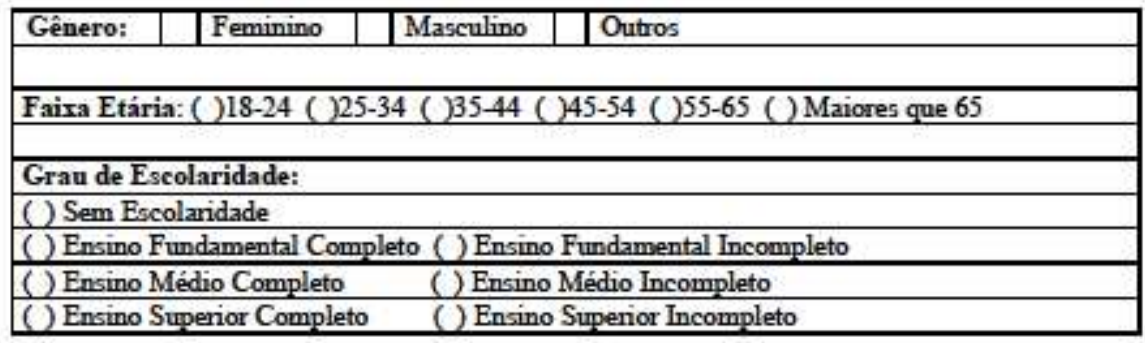

1. AS ÁRVORES NÃO DEVERLAM SER PLANTADAS NAS CIDADES.

\begin{tabular}{|c|c|c|c|c|c|}
\hline $\begin{array}{c}\text { (0) Discordo } \\
\text { Plenamente }\end{array}$ & (1) Discordo & $\begin{array}{c}\text { (2) Não discordo } \\
\text { e não concordo }\end{array}$ & (3) Concordo & $\begin{array}{c}\text { (4) Concordo } \\
\text { Plenamente }\end{array}$ & NÃo SEI \\
\hline
\end{tabular}

2. AS ÁRVORES NAS CIDADES DEIXAM O LOCAL MAIS SAUDÁVEL E FRESCO.

\begin{tabular}{|c|c|c|c|c|c|}
\hline $\begin{array}{c}\text { (0) Discordo } \\
\text { Plenamente }\end{array}$ & (1) Discordo & $\begin{array}{c}\text { (2) Não discordo } \\
\text { e não concordo }\end{array}$ & (3) Concordo & $\begin{array}{c}\text { (4) Concordo } \\
\text { Plenamente }\end{array}$ & NÃO SEI \\
\hline
\end{tabular}

3. AS ÁRVORES APRESENTAM MAIS VANTAGENS DO QUE PROBLEMAS.

\begin{tabular}{|c|c|c|c|c|c|}
\hline $\begin{array}{c}\text { (0) Discordo } \\
\text { Plenamente }\end{array}$ & (1) Discordo & $\begin{array}{c}\text { (2) Não discordo } \\
\text { e não concordo }\end{array}$ & (3) Concordo & $\begin{array}{c}\text { (4) Concordo } \\
\text { Plenamente }\end{array}$ & NÃo SEI \\
\hline
\end{tabular}

4. INVESTIR EM ÁRVORES NA CIDADE É DESPERDÍCIO DE DINHEIRO PÚBLICO.

\begin{tabular}{|c|c|c|c|c|c|}
\hline $\begin{array}{c}\text { (0) Discordo } \\
\text { Plenamente }\end{array}$ & (1) Discordo & $\begin{array}{c}\text { (2) Não discordo } \\
\text { e não concordo }\end{array}$ & (3) Concordo & $\begin{array}{c}\text { (4) Concordo } \\
\text { Plenamente }\end{array}$ & NÃo SEI \\
\hline
\end{tabular}

5. MINHA CIDADE É BEM ARBORIZADA.

\begin{tabular}{|c|c|c|c|c|c|}
\hline $\begin{array}{c}\text { (0) Discordo } \\
\text { Plenamente }\end{array}$ & (1) Discordo & $\begin{array}{c}\text { (2) Não discordo } \\
\text { e não concordo }\end{array}$ & (3) Concordo & $\begin{array}{c}\text { (4) Concordo } \\
\text { Plenamente }\end{array}$ & NÃo SEI \\
\hline
\end{tabular}

\section{VOCÊ GOSTARIA QUE TIVESSE MAIS ARVORES PLANTADAS NA CIDADE?}

\begin{tabular}{|c|c|c|c|c|c|}
\hline $\begin{array}{c}\text { (0) Discordo } \\
\text { Plenamente }\end{array}$ & (1) Discordo & $\begin{array}{c}\text { (2) Não discordo } \\
\text { e não concordo }\end{array}$ & (3) Concordo & $\begin{array}{c}\text { (4) Concordo } \\
\text { Plenamente }\end{array}$ & NÃo SEI \\
\hline
\end{tabular}


UNIVERSIDADE REGIONAL DE BLUMENAU

CENTRO DE CIÊNCIAS TECNOLÓGICAS

$F \cup R \mathbf{B}$

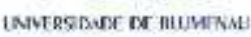
PROGRAMA DE PÓS-GRADUAÇÃO EM ENGENHARIA FLORESTAL

ESTUDO DE PERCEPÇÃO SOBRE A QUALIDADE DA ARBORIZAÇÃO URBANA

7. VOCÊ PERCEBE QUE A ARBORIZAC̣ÃO ATRAI A FAUNA/PÁSSAROS?

\begin{tabular}{|c|c|c|c|c|c|}
\hline $\begin{array}{c}\text { (0) Discordo } \\
\text { Plenamente }\end{array}$ & (1) Discordo & $\begin{array}{c}\text { (2) Não discordo } \\
\text { e não concordo }\end{array}$ & (3) Concordo & $\begin{array}{c}\text { (4) Concordo } \\
\text { Plenamente }\end{array}$ & NẤ SEI \\
\hline
\end{tabular}

8. EM SEU PONTO DE VISTA VOCÊ ACREDITA QUE ARBORIZAC̣Ão PODE ATRAIR TURISTA PARA A CIDADE? ( ) SIM ( ) NÃo

Se sim de que maneira:

9. VOCÊ AJUDARIA COM UMA CONTRIBUTÇ̃̃o FINANCEIRA PARA A MANUTENÇÃO DAS ÁRVORES DA SUA CIDADE?

( ) Sim ( ) Não

Se sim:

( ) Contribuiria 5,00 por ano

( ) 5,00 a 10,00 por ano

( ) $>10,00$ por ano

( ) Outras formas de contribuição:

Observações: 